\title{
A busca de padrões de direitos trabalhistas no comércio internacional
}

\author{
JOHN D. FRENCH
}

$\mathrm{P}$ ROPOSTAS PARA UMA CLÁUSUla social ou trabalhista internacional em acordos de comércio entre as nações foram apresentadas pela primeira vez na década de 70. Contudo, a pressão por um padrão internacional para os direitos trabalhistas só conseguiu destaque no fechamento da Rodada Uruguai do Acordo Geral de Comércio e Tarifas (General Agreement on Trade and Tariffs - GATT). Os meses que antecederam o encontro do GATT em Marrakech, em abril de 1994, foram marcados por polêmicas devido à iniciativa conjunta dos Estados Unidos e da França de incluir formalmente o tópico de uma cláusula social na agenda da Organização Mundial do Comércio (OMC), que então seria fundada. Embora o lance de última hora tenha sido rejeitado, o encontro de Marrakech concedeu às propostas sindicais em favor de uma cláusula socialinternacional credibilidade muito maior no cenário das nações. Considerando-se um sistema multilateral de comércio mundial que era totalmente inocente quanto a qualquer função ou vocação social explícita, é fato realmente notável que, a um só tempo, uma proposta totalmente secundária, feita pelo movimento sindical internacional, tenha influenciado a discussão do comércio mundial e das relações entre as nações.

A mudança não se deve inteiramente à polêmica de Marrakesh. Pelo contrário, penso que na última década houve uma mudança sutil, mas não pouco significativa, do terreno em que se avalia o comércio internacional. Número cada vez maior de participantes e observadores de relações internacionais hoje reconhece ou até começa a empregar termos como dumping social ou déficit social no comércio internacional. E muitos outros termos referindo-se à conveniência ou viabilidade de uma cláusula social do GATT/OMC entraram no debate. De fato, a discussão cresceu apesar - ou talvez até mesmo por causa - da ambigüidade e da falta de clareza que encontramos na definição de objetivos, natureza ou funcionamento de uma cláusula social.

Além disso, a discussão das dimensões sociais do comércio no início da década de 90 também sofreu a influência de acontecimentos distintos, porém 
paralelos, especialmente da adoção por parte da Comunidade Européia da Carta dos Direitos Sociais Básicos dos Trabalhadores em 1989, ou do acréscimo do acordo trabalhista ao Nafta em 1993.

A importância e a atualidade da cláusula social no cenário mundial transparecem num despacho recente da Reuters, de 31 de maio de 1995, divulgado pelo jornal Excelsior da cidade do México. O artigo fazia a cobertura de uma visita a Nova Déli do novo presidente da OMC, Renato Ruggiero, candidato que, apoiado pela Europa, derrotou um adversário asiático e conseguiu o posto pela renúncia de Carlos Salinas de Gortari, candidato apoiado pelos Estados Unidos. O artigo enfatizava o forte apoio de Ruggiero aos países pobres em sua luta contra qualquer tentativa de vincular vantagens comerciais às condições domésticas de trabalho. Indagado a respeito dos esforços da França e dos Estados Unidos nesse sentido, o funcionário da OMC foi categórico em sua oposição às assim chamadas cláusulas sociais em questões, como a do trabalho infantil.

Deixando de lado a questão de sua conveniência em termos abstratos, Ruggiero argumentou que obviamente "a solução [de tais problemas] nunca será atingida por meio de medidas restritivas ou protecionistas. Quando se levantam novas barreiras, não se está criando o clima para facilitar uma solução. [E se] uma nova barreira [comercial] é criada, você [de fato] reduz as perspectivas de crescimento nos países em desenvolvimento ... e o problema, em vez de melhorar, ficará pior.”

Tendo esclarecido essa opinião negativa, Ruggiero continuou expressando sua convicção de que a campanha da cláusula social tinha número restrito de apoiadores no âmbito internacional e provavelmente se dissiparia antes de chegar à OMC. "Se é para discutir questões trabalhistas", insistiu ele, "então deve-se fazê-lo no foro apropriado", isto é, na Organização Internacional do Trabalho em Genebra e não na Organização Mundial do Comércio.

Embora diplomático em sua expressão, o artigo da Reuters apresenta o conflito em torno da cláusula social em sua forma mais comum, menos interessante e mais imprecisa: o debate é um conflito exclusivamente norte-sul colocando os países "pobres" e "em desenvolvimento" contra uma "campanha [conduzida] pelas nações industrializadas." O artigo prossegue citando um fabricante indiano de motocicletas que ataca propostas para uma cláusula social como um esforço de tirar "uma das pequenas ou poucas vantagens que temos nos países em desenvolvimento ... nossa mão-de-obra barata.”

Resumindo, a visão da "cláusula social" como "pesadelo" apresenta essa proposta como nada mais que uma medida protecionista hostil dos trabalhadores e comerciantes do hemisfério norte, que buscam, contra toda a evidência oferecida pela teoria do comércio, obter vantagens adicionais sobre seus con- 
correntes de países menos desenvolvidos. Quanto aos governos do norte que apóiam a cláusula social, especialmente os Estados Unidos, alguém poderia apresentar o argumento, na minha opinião muito convincente, de que a cláusula social iria simplesmente oferecer à remanescente superpotência mundial mais um meio de conseguir alavancagem política sobre países do sul em eventuais conflitos futuros.

Tanto os comentários de Ruggiero quanto o despacho da Reuters captam de forma precisa a reação predominante dos comerciantes livres à cláusula social. Todavia, a apresentação da cláusula social primeiramente, se não exclusivamente, como um pesadelo protecionista através da linha divisória norte-sul, de fato contribui pouco para esclarecer os reais interesses em jogo ou a política da luta. $\mathrm{Na}$ verdade, os opositores da cláusula social ignoram completamente a oposição a essa proposta por parte dos governos da maioria dos países industrializados. E eles não mencionam a oposição deliberada à cláusula social que se percebe na maioria dos interesses comerciais do norte, precisamente os grupos que se esperaria fossem os beneficiários naturais de tal medida protecionista, juntamente com os trabalhadores do norte. E, por fim, eles nem sequer mencionam o apoio a qualquer outra versão de cláusula social por parte da vasta maioria dos movimentos sindicais no mundo em desenvolvimento - precisamente aqueles que seriam os supostos perdedores na eventualidade de sua implementação.

Pessoalmente, acho perturbador ler os debates formais que ocorreram em vários foros internacionais em torno da cláusula social. É rotina atribuir-se aos países do sul o papel de principais opositores públicos à cláusula social que está sendo apresentada pelos trabalhistas do norte. Quando vejo o fabricante indiano de motocicletas ou um representante dos industriais nigerianos levantar-se para se opor abertamente à cláusula social, fico triste porque foram exatamente a liberalização do comércio e a derrubada de tarifas protecionistas e de tratamentos nacionais preferenciais no hemisfério sul que inibiram suas próprias expectativas, como capitalistas, de desenvolver e até mesmo de manter um setor manufatureiro doméstico. Se esses manufatureiros de países menos desenvolvidos acreditam que a chave de seu futuro sucesso na indústria é a mão-de-obra barata, então realmente carregam a culpa de um monumental auto-engano.

Considero o uso de argumentos de soberania, por parte desses governos do sul, particularmente não-convincente dada a sua disposição servil de comprometer a soberania nacional no intuito de atrair os possíveis investimentos e o perdão de dívidas por parte das nações ricas e poderosas no âmbito do sistema mundial.

Mais ainda, o cinismo de Ruggiero causa-me desconforto. Ignorando totalmente as propostas concretas sobre a mesa, ele despeja o blá-blá-blá padronizado dos manuais do comércio com o propósito de atingir um hipotético caso 
extremo no qual a operação de uma cláusula social resultaria no fechamento do comércio com um país infrator.

Apesar de não subestimar a ameaça e a dimensão protecionistas representadas por uma cláusula social, posso assegurar que o repúdio altivo do Sr. Ruggiero quanto à proposta favorável a ela representa a pior espécie de desonestidade numa argumentação. Pessoalmente, fiquei sobretudo ofendido por seu gesto final, quando sugere que tais questões deveriam ser discutidas em foro apropriado - a Organização Internacional do Trabalho. Como todos sabem, e o Sr. Ruggiero sabe muito bem, a OIT tem estado sobrecarregada nos últimos anos por intenso debate a respeito da proposta de seu diretor geral a favor de um Grupo de Trabalho formado pela OIT e pela OMC para discutir a definição de uma dimensão social do comércio internacional.

Quanto à dúvida manifestada pelo Sr. Ruggiero de que talvez a questão da cláusula social jamais chegue a OMC, está sendo pouco objetivo, dado o poder que acumulam as grandes potências - como os Estados Unidos - na definição da agenda de órgãos internacionais, mesmo aqueles dirigidos por maioria de dois terços. Mas minha confiança na pertinência crescente de discussões acerca da dimensão social do comércio faz acreditar que o mundo de hoje está marcado por grande dose de ansiedade e tensão vinculadas à sensação de que perdemos coletivamente o controle do mundo e dos mercados nos quais estamos inseridos. Em que pesem sua ambigüidade e seu caráter utópico, as propostas de uma cláusula social estão desempenhando função extremamente salutar ajudando a concentrar a atenção sobre como lidar com a natureza interméstica do transe mundial da atualidade.

Não posso iniciar a discussão de hoje sobre propostas para a criação de uma dimensão social no sistema do comércio internacional sem apresentar uma perspectiva mais ampla acerca da natureza do comércio e do papel da teoria clássica do livre comércio. Como defensor de uma abordagem progressista do comércio, que é por natureza tanto socialmente consciente quanto antihegemônica, recomendo muito o excelente livro do cientista político Steven Sanderson, da Universidade da Flórida, The politics of trade in Latin American development [A política do comércio no desenvolvimento da América Latina] (Stanford, Stanford University Press, 1992). Alguns de vocês talvez conheçam sua obra anterior sobre populismo agrário no México.

Ao fazer tal recomendação, gostaria de sublinhar a profundidade e originalidade da abordagem de Sanderson, que não é refém da teoria capitalista do comércio, nem da superada teoria da dependência. O livro, para usar os termos do autor, é um exercício em "economia política histórica", que trata, de modo 
integrativo a negligência da principal dimensão do comércio internacional na região: "o fenômeno social e político por trás da política do comércio" (p. 1-2).

Numa época em que o discurso do comércio passou a ocupar posição central na vida política e na administração pública, constitui fraqueza política e intelectual o fato de os estudiosos do comércio internacional continuarem dominados pela combinação de áridas tabelas estatísticas e equações com estrutura axiomática não analisada de primeiros princípios, tais como vantagens comparativas, eficiência e troca mutuamente vantajosa - que, juntas, constituem a sabedoria oficial sobre o comércio.

Nas palavras de Sanderson, a teoria do comércio e a ação política baseiamse em "convicção estilizada e até agora mal examinada [como Ruggiero mostrou acima] de que mais comércio significa maior bem-estar nacional, eficiência econômica, fluxos de capital e outras medidas de progresso econômico" e, eu poderia acrescentar, modernidade - a tão decantada meta do último qüinqüênio (p. 5). Esse conjunto de pressupostos não provados vem acompanhado de uma insistência sistemática, se bem que muito conveniente, de separar radicalmente o comércio da história, da sociedade, da política e da moralidade (uma crítica freqüentemente repetida por católicos e cristãos).

Contrastando com isso, o objetivo de Sanderson é precisamente "conceituar os termos políticos do comércio, ... [o que] implica avaliar o próprio significado de desenvolvimento e novamente associá-lo ao comércio, incluindo-se uma nova perspectiva de recursos em relação ao comércio e ao desenvolvimento" (p. 9). A isso eu acrescentaria, com o seu aval, que precisamos também introduzir uma nova perspectiva social com relação ao comércio e ao desenvolvimento; ou seja, que precisamos aguçar nosso entendimento dos termos sociais do comércio tendo em vista tanto os inquestionáveis benefícios quanto a realidade nua e crua dos custos comerciais.

Na minha opinião, a abordagem de Sanderson nos propicia entendimento equilibrado do comércio internacional, que não é apresentado nem como bête noire nem como salvação da América Latina. Na verdade, afasta-se do simplório dogma nacionalista ou da dependência, com seu pessimismo generalizado com relação ao comércio e a sua impermeabilidade às realidades empíricas. O que temos em Sanderson é uma perspectiva necessária e bem equilibrada, que consegue enfatizar, com muita força, a verdade fundamental de que "os Estados Unidos são absolutamente indispensáveis para a prosperidade da América Latina" na década de 90, ao mesmo tempo em que reconhece essa dependência como sendo "em igual medida um problema e um trunfo" (p. 212).

Acima de tudo, ele nos lembra de que a história demonstra que mesmo "nas melhores condições ... os lucros do comércio ... cresceram irregularmente, 
provocando conflitos políticos em nível internacional [ocasionalmente entre norte e sul, mas com maior freqüência entre poderosos países ou blocos rivais no comércio] ... e [provocaram conflitos políticos] no nível doméstico [na forma de disputas] em torno da distribuição de lucros do comércio (ou de sua ausência) para o desenvolvimento".

Sanderson aponta diretamente as realidades que se escondem por trás de tanta retórica política e tanto palavreado intelectual envolvendo o comércio no mundo contemporâneo. Nas palavras dele, de modo algum depreciativas, o atual "sistema de comércio internacional está construído sobre a virtude da maximização global da produção e da eficiência em produzir mais bens e serviços para um mundo em expansão." Contudo, embora não descartando avisos de economistas de que "o mundo não é suficientemente rico para desprezar a eficiência," Sanderson observa com muita razão que "até em economia ... a eficiência é um conceito de curto prazo ... [e que comerciantes livres do norte] jamais fizeram uma ligação convincente entre a teoria do comércio e o desenvolvimento econômico", ainda deixando o campo aberto às críticas de Gunnar Myrdal ao seu "estranho isolamento ... em relação aos fatos da vida econômica".

De maneira extremamente significativa, a meu ver, ele nos lembra uma verdade histórica maior acerca do comércio ao longo dos últimos cem anos, um ponto fundamental ausente em muitos debates da ação política da atualidade: "a divisão internacional do trabalho" no mundo moderno jamais discutiu "a divisão inter ou intranacional dos lucros visando ao bem-estar internacional. Não se estipulou como o sistema internacional regulamentaria a distribuição de renda para garantir o desenvolvimento dos segmentos mais pobres da economia mundial [como a África]. Também nada se mencionou sobre as estratégias de desenvolvimento nacional que poderiam prejudicar ou favorecer a quota individual de cada país ... [nem se discutiu] a justa distribuição daqueles lucros [do comércio] internamente." Esses são os pontos que uma abordagem progressista do comércio deve colocar na agenda dos promotores da ação política e dos políticos contemporâneos.

$\mathrm{Na}$ colocação detalhada de Sanderson, "a criação global da riqueza no mundo é uma précondição necessária mas insuficiente para o crescimento econômico, que em si não é necessariamente o mesmo que desenvolvimento. A ligação entre o bem-estar internacional - por meio da expansão do comércio - e a economia nacional - por meio do crescimento em países subdesenvolvidos - é uma questão política. E a conexão do crescimento econômico total no seio de países subdesenvolvidos com o genuíno crescimento sobre bases amplas é [também] uma questão política," observação que é cada vez mais verdadeira, acrescentaria eu, mesmo para os países desenvolvidos, marcados por uma distribuição cada vez mais irregular e distorcida da riqueza apesar do crescimento econômico (p. 32-33). 
Se não quisermos ser deliberadamente ingênuos, devemos reconhecer que o regime capitalista de comércio internacional, nos séculos XIX e XX, e sem dúvida no século XXI, "foi [e é] claramente destinado aos vencedores" sem dar muita atenção a "os vencidos na distribuição de valores econômicos no sistema." $\mathrm{Na}$ verdade, a superabundância do discurso do comércio acerca das virtudes da competição e acerca do comércio ampliado como uma situação de eu-ganho-vocêganha, parece ter cegado muitos observadores para a verdade escondida na metáfora: no mundo de hoje, não há jogos com ganhadores que não tenham simultaneamente perdedores.

Afinal de contas, a esperança e a promessa, no caso da entrada do México para o Nafta, consistiam em apostar num ganhador, isto é, nos Estados Unidos, e assim fazer com que o México, na melhor das hipóteses, também fosse um ganhador ou, na pior, que não acabasse sendo um perdedor na selva da economia global da atualidade. A lógica extremamente convincente dessa proposição sofreu, é óbvio, um sério golpe no México desde dezembro de 94; talvez seja muito cedo para tirar quaisquer conclusões, mas é difícil não ser assaltado por algumas dúvidas sobre a possibilidade de o México vir a ser de fato o perdedor.

Não consigo, neste ponto, evitar uma observação sobre o caso de Carlos Salinas, que promoveu entusiasmada visão utópica de um México do Primeiro Mundo baseada na pior forma de "realismo extremista", para usar um termo do sociólogo C. Wright Mills. Num sentido, Salinas seguiu a lógica aparentemente perversa que muitas vezes tem caracterizado os fracos no cenário mundial. Se os pobres em grande parte da América Latina se comportaram passivamente, a explicação parcial desse procedimentos está no fato de tantos terem sido convencidos de que nós precisamos antes ajudar os ricos a se tornarem mais ricos se quisermos que também os pobres enriqueçam. De modo paralelo, o projeto neoliberal de Salinas e de tantos outros estadistas da região baseou-se num cálculo semelhante: precisamos ajudar as nações ricas e poderosas se nós como nação quisermos também conseguir riqueza e poder.

Essas perspectivas, num tempo de grande crise e incerteza, foram reforçadas pela volta do fatalismo geográfico que por tanto tempo havia marcado as elites políticas da América Latina antes da revolução de Cuba: a gosto ou a contragosto, nenhum governo da região pode resistir aos desejos e planos de ação dos Estados Unidos. Vendo por esse ângulo, não encontro absolutamente nada surpreendente no atual entusiasmo latino-americano a favor de uma integração com os Estados Unidos, totalmente dependente e subordinada. Se isso significar alguma coisa, trata-se na realidade do mais previsível dos velhos planos de ação na região, enfeitado com uma roupagem extremamente falsa de novidade, modernidade e mudança. 
Com Sanderson, compartilho a convicção de que a história é tudo menos palavrório absurdo e de que o poder continua sendo a característica número um e realmente central em todas as relações humanas - sejam de natureza política, sejam de mercado. No caso de Sanderson, ele se esforça para reformular nosso entendimento de comércio perguntando "em que grau a maximização de recursos através do comércio" deveria ser avaliada a partir de uma "perspectiva de recursos" meio-ambiental (p. 143). Somando a essa agenda ampliada, eu gostaria de reiterar meu apelo pessoal em favor do enfoque da atenção intelectual e da vontade política sobre a dimensão social do comércio; isto é, a ligação entre os fluxos comerciais, o bem-estar social e nacional e as questões de eqüidade tanto no nível internacional quanto no doméstico. Isso é o que queremos dizer quando levantamos a questão da dimensão social do comércio; o trabalho mal se iniciou.

Sinto-me extremamente atraído para o debate global em torno da cláusula social ou da dimensão social do mundo do comércio porque, na minha opinião, ele abre a possibilidade de tratar simultaneamente da divisão dos benefícios do comércio, seja em nível internacional entre os países, seja em nível doméstico no âmbito de cada país. Nesse sentido, a dimensão social é acima de tudo uma abordagem interméstica que, abrangendo a esfera internacional e a doméstica, aponta alternativas possíveis para alguns dos aspectos mais ameaçadores do mundo de hoje: a crescente desigualdade internacional entre nações, especialmente norte-sul, e dentro de nações quer no norte quer no sul.

Hoje, apresentarei um relatório do progresso das controvérsias conforme se desenrolaram no GATT/OMC e na Organização Internacional do Trabalho. No entanto, essa função puramente descritiva e informativa é muito menos importante do que a questão analítica vital: saber se e de que modo a abordagem da dimensão social ou da cláusula social do comércio oferece soluções adequadas para esses problemas vitais.

Deixarei que cada um de vocês avalie se a dimensão social merece o investimento de capital intelectual e político que será exigido para realmente colocála em seu lugar na ordem internacional. E mostrarei os argumentos fundamentais dos opositores de uma clausula social internacional, que até agora conseguiram todas as vantagens em cada um dos confrontos no âmbito do sistema internacional: a Rodada Uruguai inicial, o encontro de cúpula do GATT em Marrakech em 1994 e os debates na OIT em 1994-1995.

O que estou tentando fazer nesta apresentação é propiciar a discussão mais abrangente e honesta possível da situação presente do debate no âmbito do sistema internacional e do movimento trabalhista mundial acerca da questão da cláusula social. Espero, sobretudo, apresentar-lhes uma amostra da natureza ainda incipiente das propostas atuais e ao mesmo tempo identificar, com base nos 
próprios debates dos trabalhadores, as dificuldades e problemas fundamentais enfrentados na elaboração de uma proposta que seja realmente internacional em sua abrangência e positiva em seu resultado tanto para os sindicatos e trabalhadores do norte quanto para os do sul.

Portanto, minha apresentação hoje está longe de ser simplesmente um resumo em benefício da assim chamada cláusula social, embora seja a favor, e isso não deverá causar surpresa alguma, da incorporação ao comércio internacional de uma dimensão social cuidadosamente trabalhada. De fato, penso que há profundos problemas de ordem intelectual, econômica, política e até moral acompanhando algumas versões da cláusula social quando se avalia - como vim fazendo ao longo de minha obra mais extensa acerca de trabalho e livre comércio nos últimos quatro anos - à luz do objetivo superior de reconhecer interesses trabalhistas divergentes no norte e no sul, num esforço de lançar as fundamentações para o desenvolvimento de uma plataforma comum para o trabalho no âmbito mundial. Há muito tempo concluí que a consecução de tal objetivo requer o máximo de discussão obstinada, uma dose de honestidade impiedosa e uma recusa para tolerar hipocrisia e evasividade - sobretudo quando provêm dos que apóiam a nossa própria posição num determinado debate.

\section{Perspectivas para a dimensão social no terceiro milênio}

Alguns acreditam que a Cláusula Social deveria ser vista como efetivamente morta e derrotada depois do resultado no Encontro de Marrakech e na OIT.

Muitas vezes observou-se que, com freqüência, os seres humanos tendem a acreditar ser o único horizonte existente aquele que pode ser visto de onde já estamos. Isso talvez seja particularmente verdade no nosso caso, dada a dificuldade da Rodada Uruguai das negociações do GATT; a tentação é supor que o consenso internacional no ponto em que se encontrava no final dos anos $80 \mathrm{e}$ início dos 90, em torno de propostas inovadoras vinculadas ao comércio, tais como cláusulas sociais, continuará sendo o limite externo. Permitam-me examinar alguns dos argumentos que poderiam levar alguém a uma visão pessimista das propostas para a dimensão social.

Será que toda a dimensão social do comércio é simplesmente complicada demais, muito confusa e excessivamente conflitante para ser tratada através do sistema do comércio mundial?

Contrariando isso, a inclusão dos Direitos de Propriedade Intelectual (IPR) no resultado final da Rodada Uruguai do GATT sugere que interesses altamente conflitantes não são, em si e por si sós, obstáculos ao alargamento da abrangência 
Quadro 1

Convenções da OIT: propostas para inclusão em uma Cláusula "Social" ou de "Direitos Trabalhistas" no Comércio Internacional, 1972-1994

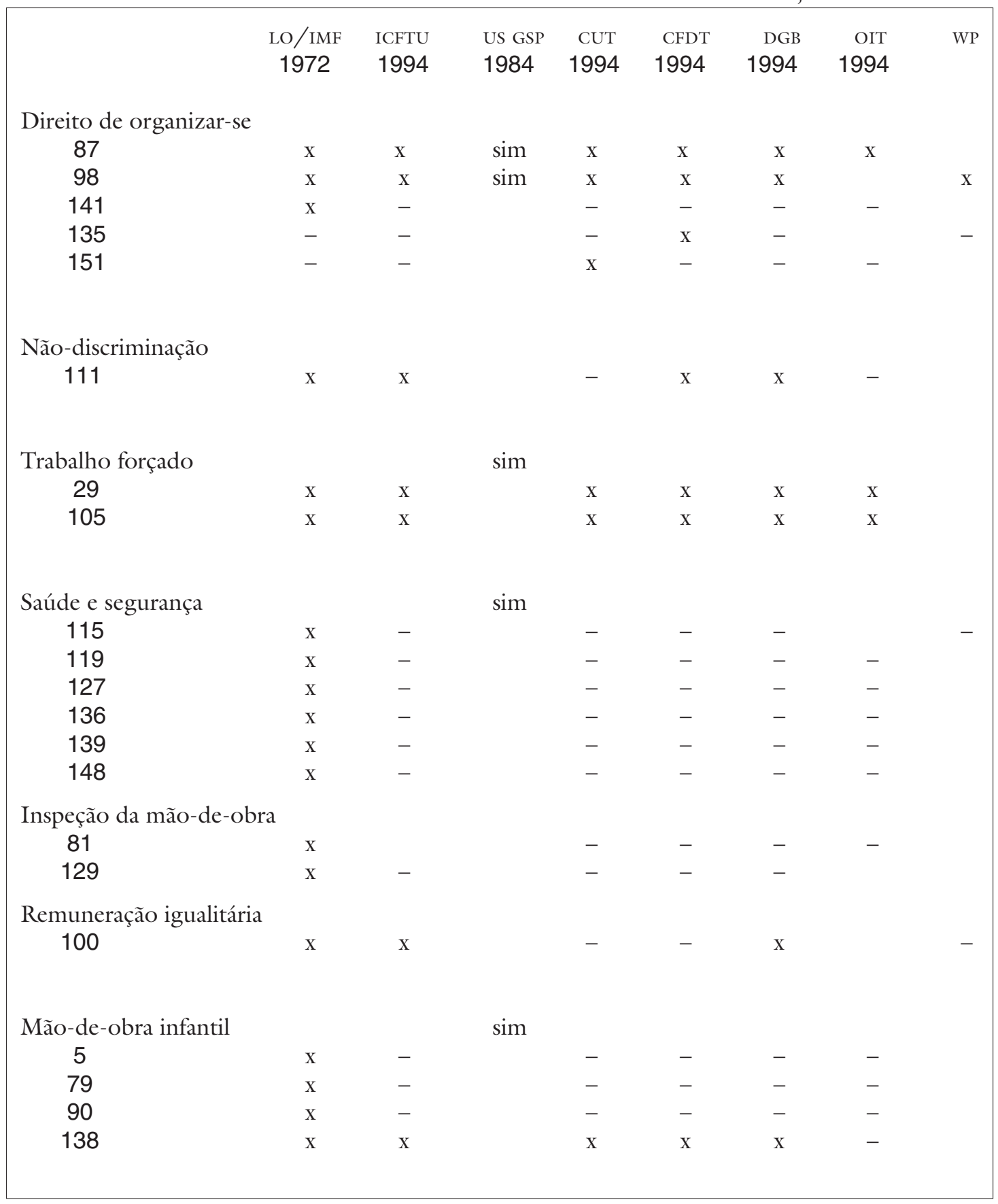

Elaborada por John D. French, Duke University

LO/IMF = Landsorganisatione i Sverige [Federação Sueca de Sindicatos Comerciais]; ICFTU = International Confederation of Free Trade Unions [Confederação Internacional de Sindicatos de Comércio Livre]; US GSP = U.S. Generalized System of Preferences [Sistema Geral de Preferências dos Estados Unidos]; CUT = Central Única dos Trabalhadores; DGB= Deutscher Gewerkschaftsbund [Confederação Alemã de Sindicatos do Comércio]; OIT = Organização Internacional do Trabalho; WP= Working Party [Partido Trabalhista] 
da arena comercial. No fim das contas, antes da OMC os Direitos de Propriedade Intelectual eram um campo muito complexo, marcado pela falta de clareza legal e pelas confusões no que se refere a definições e jurisdições; afinal, antes da OMC todo esse problema era tratado como "uma questão de ação voluntária por parte dos estados" fora do sistema multilateral de comércio conhecido como GATT.

Todavia, a aplicação concentrada de energia intelectual foi suficiente para esclarecer os desafios analíticos implicados na operacionalização dos Direitos de Propriedade Intelectual por meio de um acordo. E a mobilização da vontade política mostrou-se no fim capaz de introduzir um novo regime de obrigações internacionais para esses direitos no âmbito da nova OMC. Eu também poderia enfatizar, a esse respeito, o outro aspecto importante, precedente do direito de propriedade intelectual: antes da OMC; a essência da disciplina do GATT baseavase no "que os governos não estavam autorizados a fazer em vez de voltar-se para o que eles tinham de fazer." Contrastando com isso, na seção detalhada que no novo acordo trata desses direitos, os países signatários assumem agora direitos e obrigações precisos, incluindo-se a reformulação das leis domésticas, não só baseados em direitos de propriedade intelectual especificados e reconhecidos internacionalmente mas também especificando em detalhe os procedimentos a serem tomados (Sela).

Até mesmo a política do poder pela qual os Direitos de Propriedade Intelectual foram incorporados no GATT sugere, a meu ver, que não deveríamos de forma alguma excluir as perspectivas de uma cláusula social no futuro. Afinal, uma pressão suficiente por parte de um punhado de agentes internacionais especialmente os Estados Unidos - mostrou-se capaz de impor os Direitos de Propriedade Intelectual num âmbito internacional marcado por enormes disparidades de poder. E lembrem-se, foram os Estados Unidos e, em grau menor, a União Européia (especialmente a França) que constituíram os principais patrocinadores das propostas de uma cláusula social nos últimos dez anos.

Em outras palavras, os opositores da cláusula social dos Países Menos Desenvolvidos (LDC) têm poucas probabilidades de determinar o resultado desse futuro debate se poderosos agentes do norte tiverem de fato decidido sobre a rota da cláusula social. Dada sua extrema dependência com relação ao comércio e aos investimentos do norte, esses países são incapazes de oferecer resistência coletiva a uma pressão em prol dessa cláusula. Esse ponto é ainda corroborado pela assimetria entre os benefícios que os países menos desenvolvidos conseguem do sistema internacional e vice-versa.

Será que a dimensão social do comércio é excessivamente normativa e utópica para ser incorporada num instrumento especializado concebido para controlar violações comerciais? 
Quadro 2

Abrangência da Cláusula Social proposta pela LO Sueca e pelo IMF em discussões da OIT, 1972-1994

Patrocínio: Confederação da LO dos Sindicatos Suecos e Federação Internacional dos Metalúrgicos (1)

19 Convenções a serem incluídas

I. Direitos humanos fundamentais
Direito de organizar-se
(Convenções 87, 98, 141)
Indiscriminação
(Convenção 111)
Trabalho forçado
(Convenções 29, 105)

II. Condições de trabalho

Saúde e segurança Convenções 115, 119, 127, 136, 139, 148)

Inspeção da mão de obra (Convenções 81, 129)

III. Mulheres e crianças

Remuneração igualitária (Convenção 100)

Mão-de-obra infantil (Convenções 5, 79, 90, 138)

Elaborado por John D. French

Aqui, eu apontaria a incorporação das questões ambientais no documento final da Rodada Uruguai do GATT. Chamaria particularmente atenção para a única grande inovação que distingue o Preâmbulo do GATT de 1949 do Preâmbulo quase idêntico da nova Organização Mundial do Comércio: a presença de uma cláusula proclamando que uma das metas da OMC é conseguir "o melhor uso possível dos recursos do planeta de acordo com o objetivo de um desenvolvimento sustentável”.

Sou realista demais para confundir uma proclamação virtuosa com uma conclusão de que a nova OMC é um acordo ecológico. Fica óbvio, nesse exemplo, que a incorporação do discurso ambientalista ao GATT em pouco em comum com as estruturas poderosas e impositivas que o mesmo acordo estabeleceu para reger os Direitos de Propriedade Intelectual. Obviamente, a questão desses direitos envolve a pressão por lucros por parte de um conjunto específico de poderosos agentes privados. Assim, a dinâmica dos Direitos de Propriedade Intelectual é muito diferente daquela das questões ambientais envolvendo um bem público que não se pode converter imediatamente em lucro privado. 
Ao mesmo tempo, porém, a inclusão do discurso ambientalista no GATT abre o caminho para lances futuros visando a transformar palavras em realidade. E certamente sugere, mesmo que isto cause horror aos puristas do livre comércio, que um campo de ação política pode de fato ser predominantemente normativo e apenas imperfeitamente econômico - como no caso do meio-ambiente - e ainda assim obter sucesso dentro do GATT. O ponto essencial é outra vez a política do comércio: já ficou estabelecido na opinião pública internacional, especialmente no norte, onde isso interessa, que a única barreira à incorporação no GATT de outros assuntos não-econômicos ou semi-econômicos é a ausência de consenso suficiente. A esse respeito, é instrutivo o fato de que o Preâmbulo da OMC não apresente uma declaração virtuosa semelhante a respeito do comércio mundial. Isso reflete, argumentaria eu, a fraqueza do consenso internacional nesses assuntos durante a década de 80. Todavia, não há nada, pelo que eu consigo ver, sugerindo que os obstáculos no caminho da dimensão social não possam ser de fato superados no futuro.

\section{Quadro 3}

Abrangência da Carta Social proposta pelo ICFTU e pelo GATT, incluindo convenções da OIT e ratificações nacionais

Patrocínio: Confederação Internacional de Sindicatos Livres (2)

Número de países ratificadores (1993) para as 7 convenções da OIT propostas para inclusão:

109 Convenção 87: “Convenção sobre a liberdade de associação e proteção aos direitos de organizar-se"

123 Convenção 98: “Convenção sobre a aplicação dos princípios do direito de organizar-se e negociar coletivamente"

135 Convenção 29: "Convenção sobre trabalho forçado e mão-de-obra escrava"

112 Convenção 105: "Convenção sobre a abolição do trabalho forçado"

118 Convenção 111: "Convenção sobre discriminação referente a emprego e ocupação"

135 Convenção 100: "Convenção sobre remuneração igual para trabalhadores homens e mulheres por trabalho de valor igual"

46 Convenção 138: "Convenção sobre idade mínima para admissão no emprego"

Elaborado por John D. French

Estudos AvanÇados 10 (27), 1996 
Afinal, um consenso internacional em torno do enfoque de uma ação política específica depende, em grande parte, da mobilização da atenção política e intelectual sustentada voltada para um dado problema. No caso da dimensão social do comércio, é triste, mas é verdade, que um número por demais reduzido de acadêmicos e promotores de ação política devotaram séria atenção a essas questões desde os anos 70. Essa falta de progresso é ainda mais facilmente entendida quando se reconhece que a maioria dos movimentos trabalhistas nos mesmos países desenvolvidos que desovaram o ambientalismo mantiveram-se em atitude defensiva dentro de suas sociedades durante grande parte do tempo, destroçados por crises, contratempos e confusão geral.

Pessoalmente, acredito que a dimensão social do comércio atingiu um momento de maturação e transição e agora está sendo reconhecida como questão vital nas relações internacionais. É óbvio que o interesse foi aguçado pelo debate do NAFTA, pela altissonante disputa de Marrakech e pelas recentes controvérsias na OIT. Mas também acho que o interesse vai além das circunstâncias imediatas dos dois últimos anos. Desde a queda da União Soviética, muita atenção concentrou-se na dinâmica do sistema mundial remanescente, o sistema capitalista ancorado no GATT. Preocupações com os perfis do poder e com as implicações dessas novas realidades do poder envolvendo regiões dependentes e trabalhadores - do norte e do sul - começaram a gerar grande fermentação, e todo um corpo de estimulante trabalho intelectual está atualmente sendo feito em torno da dimensão social do comércio internacional - tudo isso num contexto em que a questão ganhou grande destaque e visibilidade pela primeira vez.

Quadro 4

Abrangência da Carta Social proposta pela Comissão da OIT sobre as dimensões sociais da liberalização do Comércio Mundial, 1994 (3)

Propõem-se que quatro Convenções da OIT sejam incluídas de um total de 174 Convenções e 180 recomendações (1992) (4)

87: "Convenção sobre liberdade de associação e proteção do direito a organizar-se"

98 “Convenção sobre a aplicação dos princípios do direito a organizar-se e negociar coletivamente"

29 "Convenção sobre trabalho forçado ou mão-de-obra escrava"

105 "Convenção sobre a abolição de trabalho forçado" ampliada para incluir "mãode-obra infantil quando organizada em condições que correspondem à escravidão" 
Quadro 5

Abrangência das Cláusulas Sociais de Organizações afiliadas à ICFTU em 1994: CUT-Brasil, CFDT França e DGB-Alemanha

\begin{tabular}{|c|c|}
\hline CUT-Brasil & (6 ao todo) \\
\hline Direito à liberdade sindical & (Convenções 87 e 151 ) \\
\hline Direito à sindicalização e negociação coletiva & (Convenção 98) \\
\hline Proibição do trabalho forçado & (Convenções 29 e 105$)$ \\
\hline Proibição do emprego de menores & (Convenção 138) \\
\hline CFDT-França & (6 ao todo) \\
\hline Idade m'nima de admissão ao trabalho & (Convenção 138) \\
\hline Proibição do trabalho forçado & (Convenções 29 e 105$)$ \\
\hline Proibição de qualquer discriminação & (Convenção 111) \\
\hline Liberdade sindical & (Convenção 87) \\
\hline Direito à negociação coletiva & (Convenção 98) \\
\hline DGB-Alemanha & (8 ao todo) \\
\hline Garantia da liberdade de associação & (Convenção 87) \\
\hline - do direito ao acordo coletivo & (Convenção 980) \\
\hline \multicolumn{2}{|l|}{ - da proteção dos representantes dos trabalhadores } \\
\hline nos locais de trabalho & (Convenção 135) \\
\hline Proibição do trabalho forçado & (Convenções 29 e 105) \\
\hline Proibição do trabalho infantil & (Convenção 138) \\
\hline Proibição da discriminação no recrutamento e no emprego & (Convenção 111) \\
\hline \multicolumn{2}{|l|}{ Igualdade salarial entre homens e mulheres } \\
\hline que realizem o mesmo trabalho & (Convenção 100) \\
\hline
\end{tabular}

Estudos AvanÇados 10 (27), 1996 
Quadro 6

Direitos Trabalhistas Básicos conforme definição dos Estados Unidos no Estatuto de Prorrogação do Sistema Geral de Preferências de 1984 (4)

Direito de associação

Direito de organizar-se e negociar coletivamente

Liberação contra toda forma de trabalho forçado ou compulsório

Idade mínima para o emprego de crianças

Condições aceitáveis de emprego no que se refere a salário mínimo, horas de trabalho, segurança e salubridade ocupacional

Elaborado por John D. French

Quadro 7

Resumo das áreas cobertas pela "Carta Comunitária de Direitos Sociais Fundamentais para Trabalhadores" da Europa (1989)

Adotado em 1989 com base num texto original elaborado pela Confederação Européia de Sindicatos (6)

1) Liberdade de movimento

2) Emprego e remuneração

3) Melhoria das condições de vida e de trabalho

4) Proteção social

5) Liberdade de associação e negociação coletiva

6) Treinamento vocacional

7) Tratamento igual para homens e mulheres

8) Informação, consulta e participação dos trabalhadores

9) Proteção à saúde e segurança no local de trabalho

10) Proteção de crianças e adolescentes

11) Pessoas idosas

12) Pessoas com deficiências físicas 
Quadro 8

Abrangência dos Direitos dos Trabalhadores conforme definição da União Européia no contexto da Convenção de Lomé e do Sistema de Preferências Garantidas

Quatro Convenções da orT estão incluídas:

Igualdade de oportunidades e tratamento no trabalho sem distinção de raça, cor, religião ou sexo.

Número máximo de horas de trabalho

Proibição de emprego de menores de 14 anos nas indústrias

Proteção à saúde e à segurança de menores e adolescentes nas indústrias

Notas

1 Arne Wangel, The ILO and protection of trade union rights: the electronics industry in Malaysia [A OIT e a proteção dos direitos sindicais: a indústria eletrônica na Malásia] In: Roger Southall (ed.), Trade unions and the new industrialization of the Third World [Os sindicatos e a nova industrialização do Terceiro Mundo], Pittsburgh, University of Pittsburgh, 1988.

2 International Confederation of Free Trade Unions [Confederação Internacional de Sindicatos Livres]. International workers' rights and trade: the need for dialogue [Comércio e direitos dos trabalhadores internacionais: a necessidade de diálogo]. IFCTU, 1994a, 6331; International Confederation of Free Trade Unions. The social clause: rationale and operating mechanisms [A cláusula social: princípios e mecanismos operacionais], IFCTU, 1994b.

3 International Labour Office, Working Party on the Social Dimensions of the Liberalization of International Trade (WP/SLD). The social dimensions of the liberalization of world trade. International Labour Organization, 1994. Document G.B 260/205

4 Sistema Econômico Latinoamericano, El 'dumping social': la politica social como politica comercial, prepared for the $x x$ Runion Extraordinaria del Consejo Latinoamericano, Mexico, D.D., 30 May-3 June 1994, SP/CL/XIX/DI no 4, p. 13

5 Sidney Weintrabu and Jan Gilbreath, The social side of trade [O lado social do comércio], In: Jonathan Lemco and William Robson (eds.) Ties beyond trade: labor and environmental issues under the NAFTA [Vínculos supra-comerciais: questões ambientais e trabalhistas sob o NAFTA], Toronto, C.D. Howe Institute and National Planning Association, 1993, p. 65 
6 Elizabeth C. De Boer and Gilbert R. Winham, Trade negociations, social charters, and the NAFTA [Negociações comerciais, cartas sociais e o NAFTA], In: Jonathan Lemco and William Robson (eds.) Ties beyond trade, Toronto, 1993, p. 21-22, 39-40

John D. French é professor da Duke University (EUA).

Texto apresentado pelo autor no Seminário Processos de Integração Regional e as Respostas da Sociedade: Argentina, Brasil, México e Venezuela, realizado nos dias 7 e 8 de agosto de 1995 no Instituto de Estudos Avançados da USP.

Tradução de Almiro Pisetta. O original em inglês - The pursuit of workers' rights standards in international trade: proposed Gatt 'social clause' as nightmarem Holy Grail or vain illusion - encontra-se à disposição do leitor no IEA-USP para eventual consulta. 